\title{
Buckling in eccentrically discharged silos and the assumed pressure distribution
}

\author{
Adam J. Sadowski ${ }^{1}$ \& J. Michael Rotter F.ASCE ${ }^{2}$
}

\begin{abstract}
Eccentric discharge in slender metal silos is known to be one of the most critical load conditions, responsible for many silo buckling disasters in the past. The high failure rate may be significantly attributed to difficulties in devising a suitable wall pressure representation for this condition. Where the flow of stored solids is eccentric and has partial contact with the wall in a slender silo, the solid exerts much lower pressures than the adjacent stationary solid. This pressure drop leads to very high local axial compression and causes buckling failure. Experimentally measured pressures indicate that a significant rise in pressure may occur just outside the flow channel, but its form and magnitude are not yet well understood because very detailed and expensive instrumentation is needed to obtain data that can define it. This paper explores the nonlinear structural behaviour and buckling of a slender metal silo with and without specific inclusion of an adjacent rise in pressure, to determine whether it is a necessary part of any design pressure representation.
\end{abstract}

To assist this investigation, the mechanics of the nonlinear behaviour of a cylindrical silo under this load condition is explored using the analogy of a propped cantilever slice-beam. Advantage is taken of a particular load condition that leads, by chance, to buckling at the same load factor for both linear and geometrically nonlinear analyses. This special case permits the detrimental effect of wall flattening and the beneficial effect of the changing prebuckling stress pattern to be explored to give a deeper insight into the behaviour. The slice-beam analogy may also be generalised to describe the nonlinear behaviour of any thin-walled cylindrical shell under meridional strip-like loads acting on part of the circumference.

Keywords: shell buckling, thin-walled metal silos, eccentric discharge, geometrically nonlinear analysis, silo design, strip loads. 
Published in: ASCE Journal of Engineering Mechanics, 139(7), 858-867.

DOI: http://dx.doi.org/10.1061/(ASCE)EM.1943-7889.0000525

\section{Affiliations}

${ }^{1}$ Research Associate, The University of Edinburgh, Scotland, UK

${ }^{2}$ Professor of Civil Engineering, The University of Edinburgh, Scotland, UK 
Published in: ASCE Journal of Engineering Mechanics, 139(7), 858-867.

DOI: http://dx.doi.org/10.1061/(ASCE)EM.1943-7889.0000525

\section{Introduction}

Eccentric discharge in slender metal silos (Fig. 1) is known to be one of the most severe load conditions and the cause of many silo buckling disasters in the past. This high failure rate is compounded by the difficulty of developing a realistic and practical model to represent the wall pressures that can be used in design. For a long time, design models for silos under eccentric discharge focused on the ultimate limit state of yielding of the silo wall under high circumferential membrane tension and bending moment (Jenike, 1967; Wood, 1983; Bucklin et al., 1990). This condition of failure is known to be exacerbated by local increases in normal pressure, which were thus emphasised in design either through overpressure factors or localised 'patches' of high pressure (DIN 1055-6, 1987; ISO 11697, 1995; AS 3774, 1996; EN 1991-4, 2006). Though such an assessment may be appropriate for concrete silos which crack easily under tension and bending, bursting failures in thin-walled metal silos are very rare. A thorough parametric study of the above codified pressure patterns was carried out by Song and Teng (2003) whose work is highly relevant to the material presented in this paper.

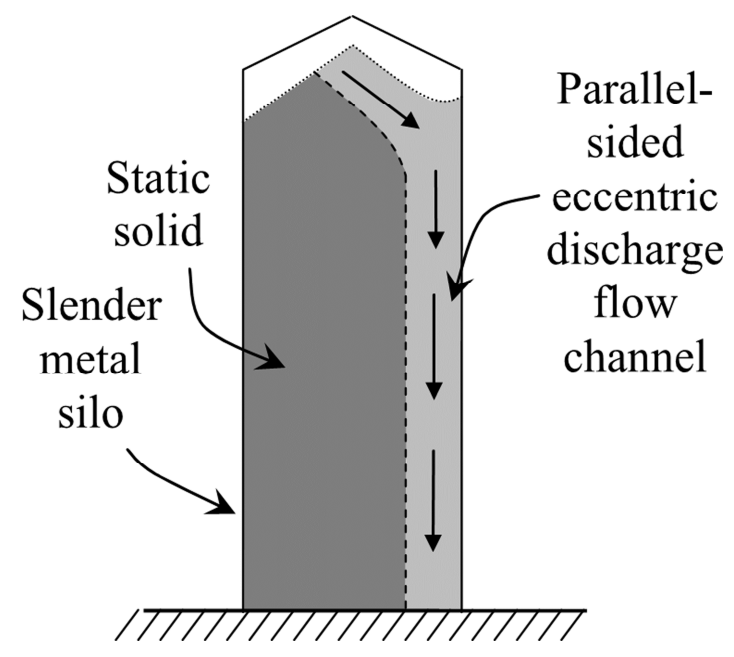

Fig. 1 - Idealised image of solids flow under eccentric discharge

It has now been recognised that the principal consequence of eccentric discharge in metal silos is early buckling failure caused by high local axial membrane compression (Rotter, 1986; 2001a; Sadowski \& Rotter, 2010; 2011a,b,c,d), a condition that is exacerbated by a local decrease in normal pressure. The first study to offer a reasonably realistic design model for the wall pressures that reproduced the critical 
Published in: ASCE Journal of Engineering Mechanics, 139(7), 858-867.

DOI: http://dx.doi.org/10.1061/(ASCE)EM.1943-7889.0000525

condition of buckling was that of Rotter (1986), based on a generalisation of the flow channel cross-section conceived by Jenike (1967) and the assumption of vertical channel sides (Figs. 1 and 2a). By analysing the vertical equilibrium of stresses in the static and flowing solid zones, Rotter's model predicts a significantly lower wall pressure in the flow channel than in the static solid, a result supported by reliable experimental evidence (e.g. Nielsen and Kristiansen, 1980; Gale et al., 1986; Chen et $a l .$, 1998). The model has since been incorporated in modified form into the European Standard EN 1991-4 (2006) on Actions on Silos and Tanks as a separate design load case both for very large silos and those where large discharge eccentricities are expected.

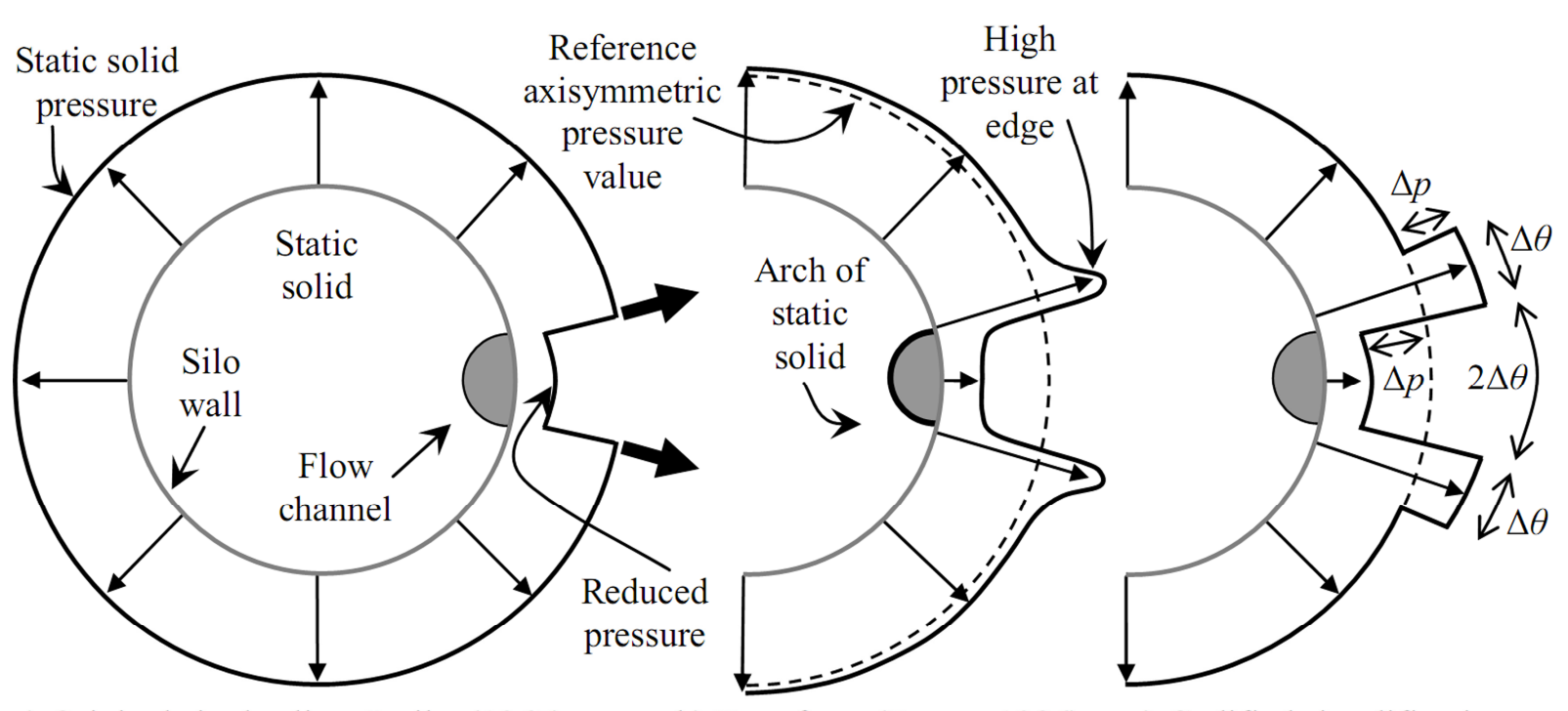
a) Original single slice, Jenike (1967)
b) True form (Rotter, 1986)
c) Codified simplification

Fig. 2 - Proposed patterns for the circumferential distribution of normal pressures on the wall of an eccentrically discharging silo

The first numerical studies using this formulation for the eccentric discharge pressures (Rotter, 1986; 2001b) showed that the low pressure in the flow channel disproportionately increases the local axial compression and precipitates early buckling failure. Such buckling failures have been found extensively in model experiments (e.g. Pieper \& Wenzel, 1964; Rotter et al., 1989; Watson \& Niland, 2009). These all display a characteristic axial compression buckle across the flow channel somewhere near midheight. There is also good experimental evidence that the static granular solid directly adjacent to the flow channel exerts an additional high normal pressure against the wall (Fig. 2b) due to the arching effect of the ring of static 
Published in: ASCE Journal of Engineering Mechanics, 139(7), 858-867.

DOI: http://dx.doi.org/10.1061/(ASCE)EM.1943-7889.0000525

material (Roberts \& Ooms, 1983; Gale et al., 1986; Ooi et al., 1990; Chen, 1996; Chen et al., 2007). This increase in normal pressure is necessary to maintain Janssen equilibrium, but no consensus has been reached either on its circumferential form or its peak value. Wishing to produce a simple conservative design description that would account for this uncertainty, the EN 1991-4 standards committee chose the rather severe form of a sharp-edged rectangular block of high pressure in the static solid adjacent to the flow channel (Fig. 2c). Although this form respects axisymmetric horizontal equilibrium, it may unnecessarily exaggerate an already very serious load pattern leading to uneconomical designs.

The objective of this paper is to investigate the effect of removing these uncertain regions of high pressure to determine whether they have a large influence on the predicted buckling strength of a typical example silo, and to determine whether this high pressure feature is necessary in practical design models. In addition, the mechanics of the geometrically nonlinear behaviour is explored using the calculated prebuckling stress pattern. The membrane theory of shells is then used to explore the prebuckling state, leading to the analogy of a propped cantilever beam, which was previously used for other purposes by Gould (1988). For ease of description, the regions of high pressure adjacent to the flow channel are hereafter more colourfully referred to as 'ears' on the pressure pattern.

\section{Example silo and applied pressure patterns}

A simple flat-bottomed cylindrical silo holding 675 metric tons of a generic granular material with similar properties to those of cement was designed to resist only concentric discharge pressures. The rules of EN 1991-4 (2006) were used to define the wall pressures, its Annex E to define the properties of the solid, and the rules of EN 1993-1-6 (2007) and EN 1993-4-1 (2007) were used to define the structural strengths. The silo had a height $H=18 \mathrm{~m}$, a radius $r=3 \mathrm{~m}$ (aspect ratio of 3, classed as 'slender') and an isotropic mild steel wall with elastic modulus $E=200 \mathrm{GPa}$, Poisson's ratio $v=0.3$ and yield stress $\sigma_{y}=250 \mathrm{MPa}$. The wall thickness $t$ was varied from $3 \mathrm{~mm}$ at the top of the silo to $8 \mathrm{~mm}$ at the base in increments of $1 \mathrm{~mm}$ in a manner to make the base of every strake critical for buckling under concentric discharge pressures only. The details of this silo design are similar to those used in 
Published in: ASCE Journal of Engineering Mechanics, 139(7), 858-867.

DOI: http://dx.doi.org/10.1061/(ASCE)EM.1943-7889.0000525

earlier studies by the authors (Sadowski \& Rotter, 2010; 2011a,b,c) and are not critical to the phenomena that this paper seeks to explore.

Table 1 - Summary of computational analyses undertaken in this study

\begin{tabular}{|c|c|c|c|}
\hline Acronym & Geometry & Assumed material law & Objective of analysis \\
\hline LA & Linear & Elastic & Reference linear stresses \\
\hline LBA & Linear & Elastic & Lowest buckling eigenvalue \\
\hline GNA & Nonlinear & Elastic & Lowest buckling load \& nonlinear stresses \\
\hline GMNA & Nonlinear & Ideal Elastic-plastic & Lowest buckling load \\
\hline
\end{tabular}

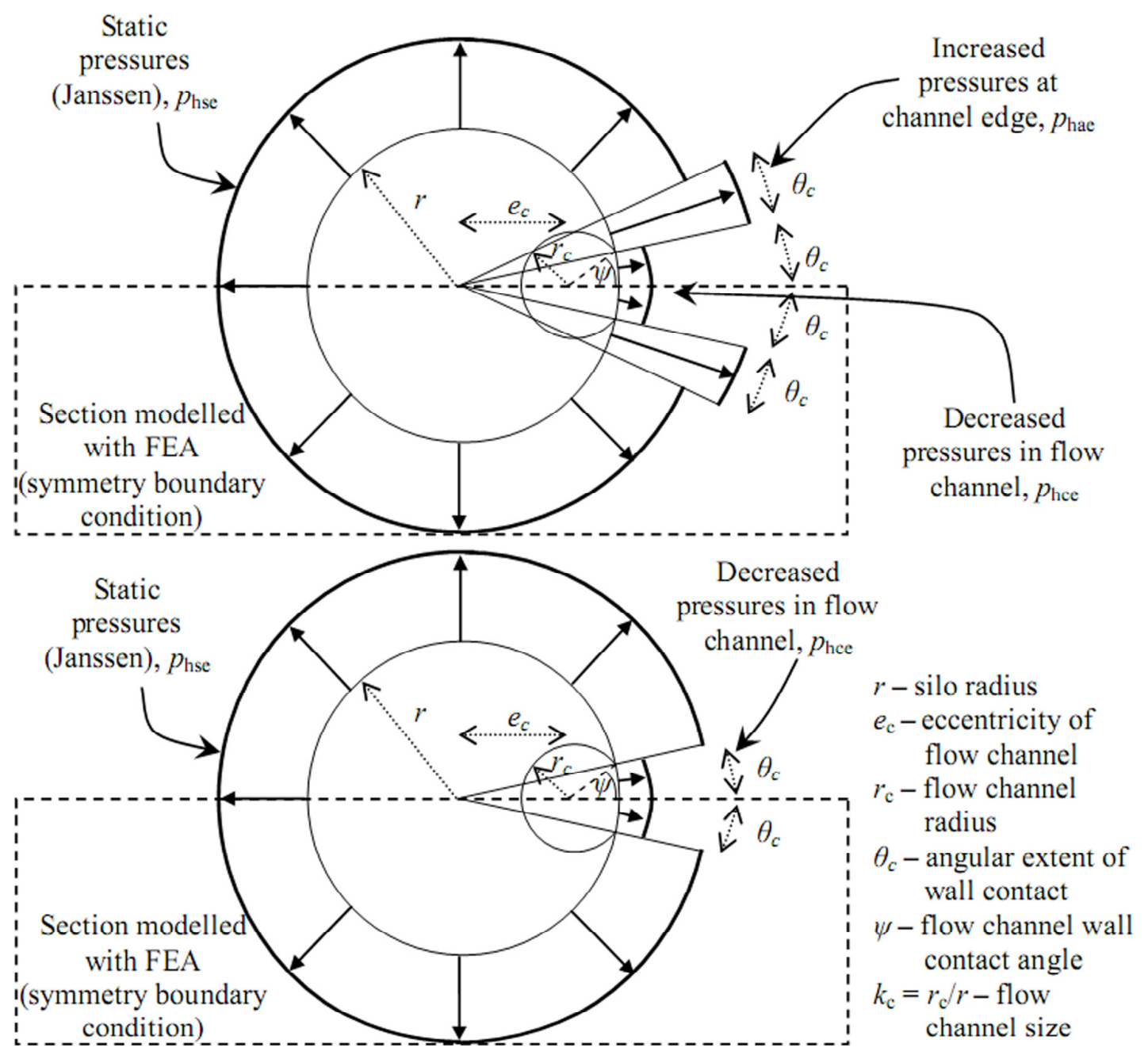

Fig. 3 - Cross-section of two eccentric discharge pressure models: descriptions including 'ears' (top) and without 'ears' (bottom)

The example silo was analysed as a thin-walled shell with the ABAQUS (2009) finite element software using four types of computational analysis: LA, LBA, GNA and 
Published in: ASCE Journal of Engineering Mechanics, 139(7), 858-867.

DOI: http://dx.doi.org/10.1061/(ASCE)EM.1943-7889.0000525

GMNA (Table 1). Only the perfect shell was analysed. The load factors for the GNA and GMNA analyses correspond to the first reported negative eigenvalues in the tangent stiffness matrix on the equilibrium path as followed by the modified Riks (1979) procedure. The materially nonlinear GMNA analyses assumed an ideal elasticplastic material law for simplicity.

The example silo was first analysed under factored axisymmetric Janssen pressures to obtain a set of load factors for the reference concentric discharge condition. The behaviour of similar silo designs under concentric discharge was previously investigated in detail by Sadowski \& Rotter (2010; 2011a,b), so these results are not discussed further here. The silo was next analysed under the eccentric discharge pressures including the 'ears' (Fig. 3, top), using three typical flow channel sizes: $k_{\mathrm{c}}=r_{\mathrm{c}} / r=0.25,0.40$ and 0.60 (Fig. 4). Finally, the silo was analysed using the alternative pressure pattern (Fig. 3, bottom) in which the static zone Janssen pressure component ( $\left.p_{\text {hse }}\right)$ was applied wherever the wall was not in contact with flowing solid, so that the 'ears' were removed (Fig. 5). These analyses used the same three flow channel sizes. Frictional tractions $p_{\mathrm{fse}}, p_{\mathrm{fce}}$ and $p_{\text {fae }}$ on all relevant parts of the wall were calculated using $p_{\mathrm{f}}=\mu p_{\mathrm{h}}$ where $\mu$ is the fully-developed wall friction coefficient.
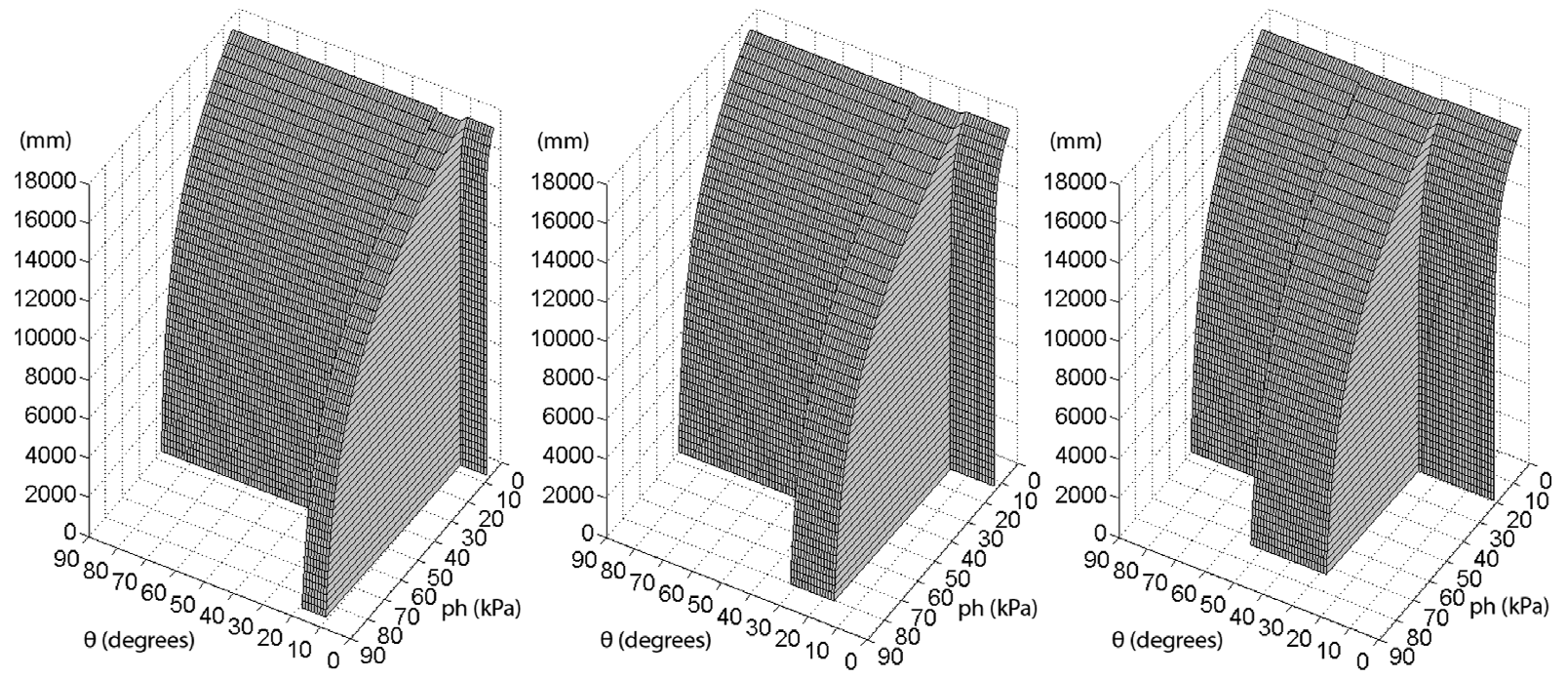

Fig. 4 -3D surface plots of eccentric discharge normal wall pressures with 'ears'.

Left to right: $k_{\mathrm{c}}=0.25,0.40$ and 0.60 
Published in: ASCE Journal of Engineering Mechanics, 139(7), 858-867.

DOI: http://dx.doi.org/10.1061/(ASCE)EM.1943-7889.0000525
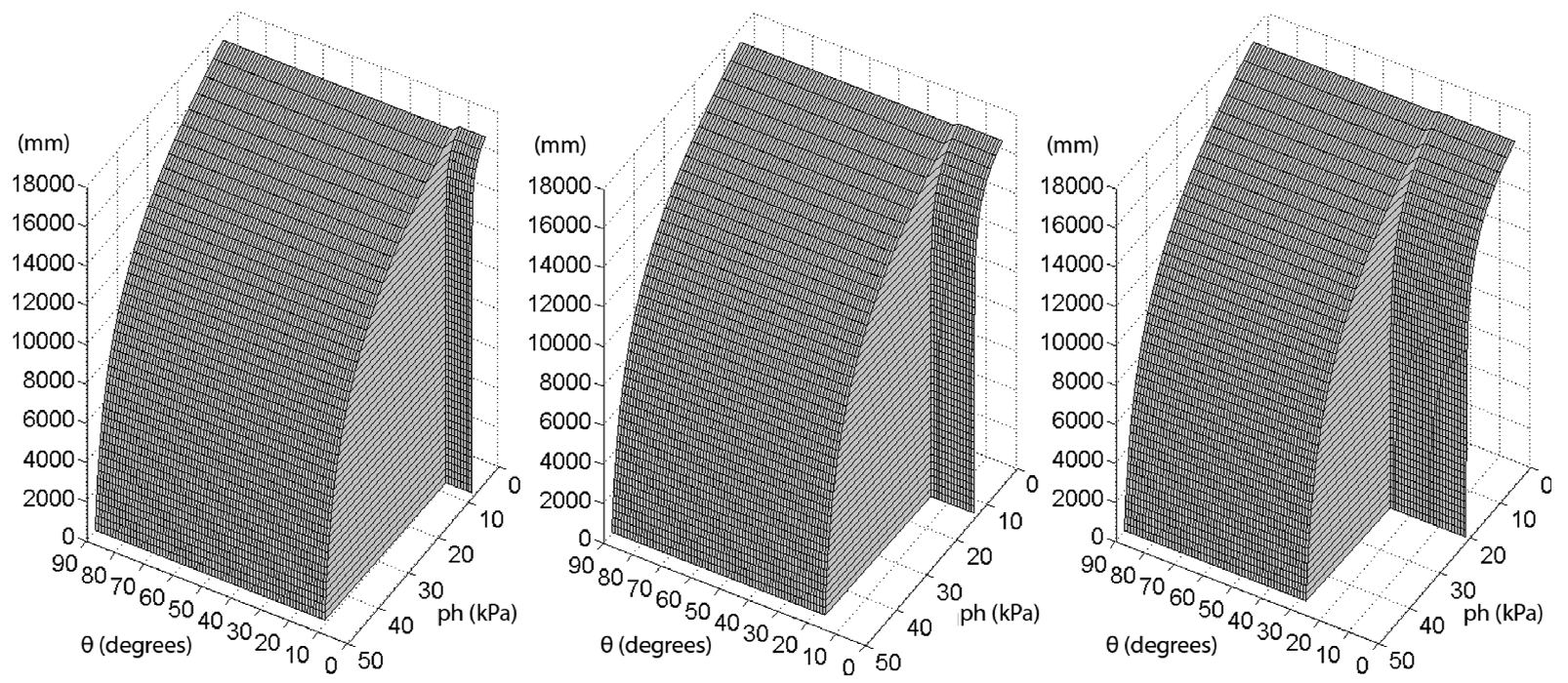

Fig. 5 - 3D surface plots of eccentric discharge normal wall pressures without 'ears'.

Left to right: $k_{\mathrm{c}}=0.25,0.40$ and 0.60

\section{Load proportionality factors at buckling}

A summary of the computed load factors at buckling is presented in Table 2 and Fig. 6. A direct comparison between the load factors at buckling under eccentric discharge with those under concentric discharge reveals the same phenomena that were reported in detail by Sadowski \& Rotter (2010; 2011a,b,c,d) and are not discussed further here. For the two larger flow channel sizes $\left(k_{\mathrm{c}}=0.40\right.$ and 0.60$)$, the eccentric discharge pressure pattern causes a large fall in the predicted buckling strength, giving load factors far below unity, corresponding to immediate buckling failure if this flow channel were to develop in a full silo. Removal of the 'ears' of the pressure distribution $\left(p_{\text {hae }}\right)$ does not change this trend or the severity of the load case, confirming that it is the decrease in pressure in the flow channel that is the primary cause of the very low buckling strength calculated under eccentric discharge.

For the smallest flow channel size $\left(k_{\mathrm{c}}=0.25\right)$, the GNA and GMNA load factors for the pressure model with 'ears' (marked in italics, Table 2) are significantly higher than the corresponding LBA factor. A detailed explanation for this phenomenon was put forward by Sadowski \& Rotter (2011c,d), who consequently advised that this pressure description should not be used with very small flow channels (approx. $k_{\mathrm{c}}<0.3$ ). The reason for this recommendation is that such small channels appear to produce conditions that lie between the stress pattern corresponding to concentric discharge 
Published in: ASCE Journal of Engineering Mechanics, 139(7), 858-867.

DOI: http://dx.doi.org/10.1061/(ASCE)EM.1943-7889.0000525

and that corresponding to 'fully-developed' eccentric discharge under larger flow channels when a geometrically nonlinear analysis is used. Given the current difficulty in predicting the size of real flow channels, it seems unlikely that small flow channel buckling predictions can actually be relied on to produce safe designs.

Table 2 - Summary of computed load proportionality factors

\begin{tabular}{|c|c|c|c|c|c|c|c|}
\hline & $\begin{array}{c}\text { Concentric } \\
\text { Janssen }\end{array}$ & \multicolumn{2}{|c|}{$\begin{array}{c}\text { Eccentric discharge } \\
\text { with 'ears' }\end{array}$} & \multicolumn{3}{|c|}{$\begin{array}{c}\text { Eccentric discharge } \\
\text { without 'ears' }\end{array}$} \\
\hline$k_{\mathrm{c}}=r_{\mathrm{c}} / r$ & 0.00 & 0.25 & 0.40 & 0.60 & 0.25 & 0.40 & 0.60 \\
\hline LBA & 6.34 & 0.30 & 0.18 & 0.24 & $\mathbf{0 . 2 6}$ & 0.28 & 0.52 \\
\hline GNA & 6.31 & 2.69 & 0.24 & 0.35 & $\mathbf{0 . 2 6}$ & 0.38 & 0.82 \\
\hline GMNA & 3.93 & 2.35 & 0.24 & 0.35 & 0.26 & 0.38 & 0.82 \\
\hline
\end{tabular}

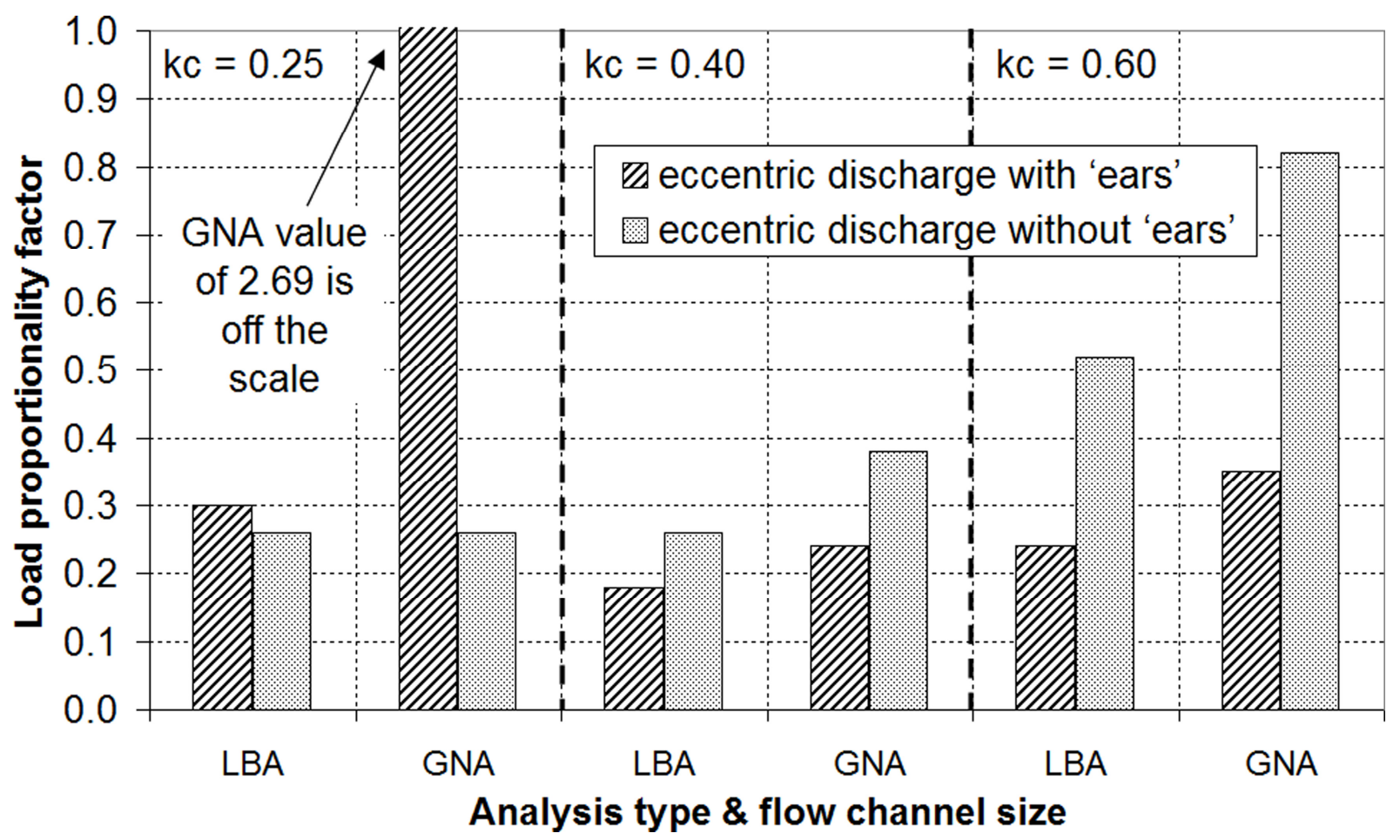

Fig. 6 - Bar chart showing LBA and GNA load proportionality factors for eccentric discharge pressures with and without 'ears'

For the larger flow channel sizes (larger $k_{\mathrm{c}}$ ), a comparison of the load factors under eccentric discharge shows that removal of the 'ears' leads to a considerable gain in the predicted LBA buckling strength of over $55 \%$ for $k_{\mathrm{c}}=0.40$ and $115 \%$ for $k_{\mathrm{c}}=0.60$. When the pressure pattern includes these 'ears', significantly higher local axial 
Published in: ASCE Journal of Engineering Mechanics, 139(7), 858-867.

DOI: http://dx.doi.org/10.1061/(ASCE)EM.1943-7889.0000525

compression develops across the centre of the channel than without 'ears'. The result is that the peak axial compressive stress resultant reaches a critical value at a lower load factor than when the 'ears' are absent. This phenomenon is illustrated in Fig. 7 using data from a linear-elastic LA analysis, though the GNA analyses exhibit the same features. The LBA load factor for both $k_{\mathrm{c}}=0.40$ and 0.60 may be closely estimated from the ratio of the peak LA axial membrane stress resultant $n_{\max }$ at the base of the 3 mm strake (the critical location for buckling under this condition) to the classical buckling value (Eq. 1). This shows that (relatively small) axial compression buckles develop when the local axial compressive membrane stress resultant is close to the classical critical value. This is later seen to be a more general criterion of wider usefulness.

$n_{c l}=t \sigma_{c l} \approx 0.605\left(\frac{E t^{2}}{r}\right)$

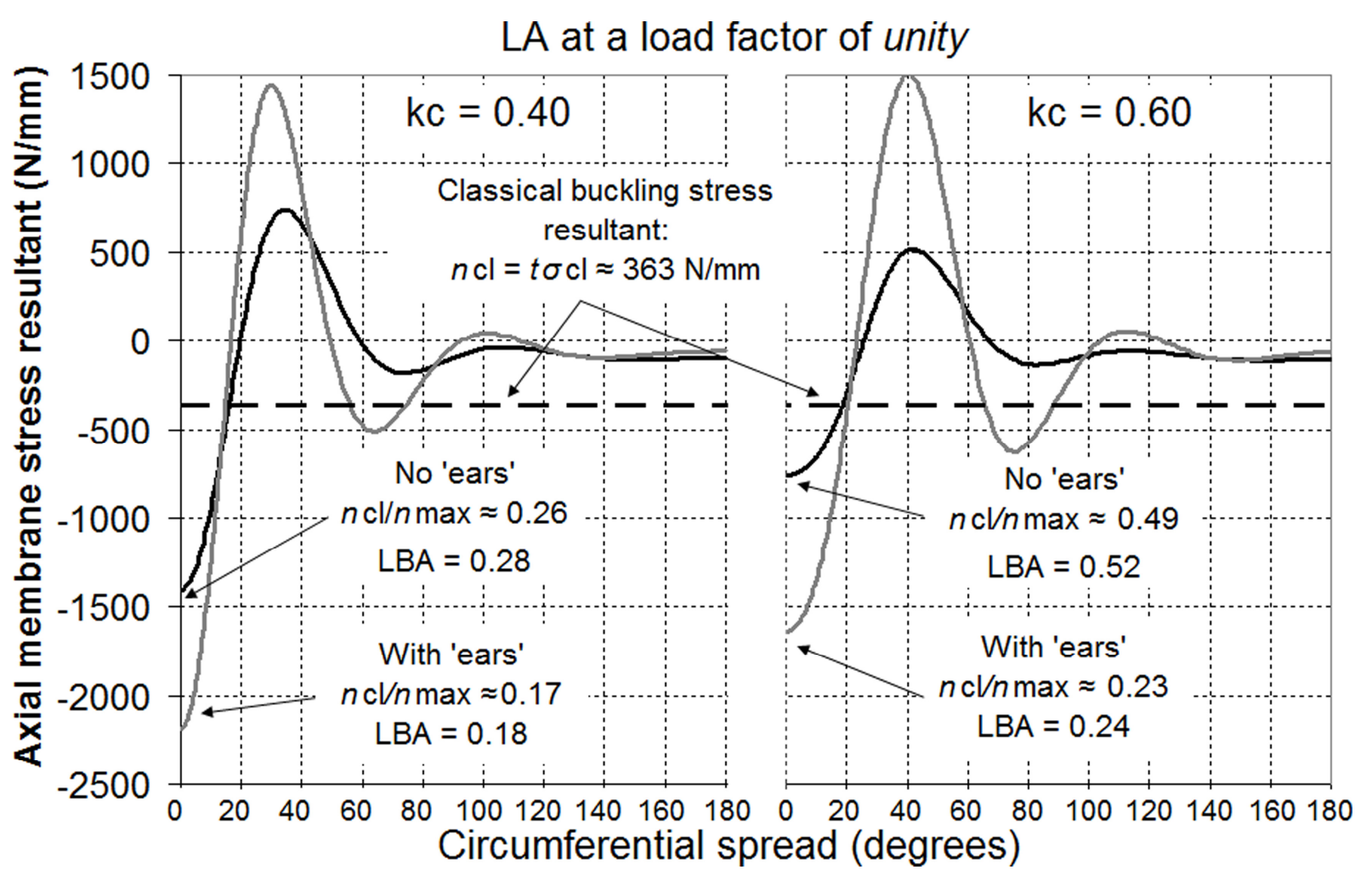

Fig. 7 - Circumferential distribution of LA axial membrane stress resultants just above the base of the thinnest $3 \mathrm{~mm}$ wall strake (load factor of unity)

Under concentric discharge $\left(k_{\mathrm{c}}=0.00\right)$, buckling occurs at the base of the thinnest (3 mm) wall strake, where the LBA and GNA buckling modes are the classic elastic axisymmetric and diamond pattern modes respectively (Fig. 8). The GMNA buckling 
Published in: ASCE Journal of Engineering Mechanics, 139(7), 858-867.

DOI: http://dx.doi.org/10.1061/(ASCE)EM.1943-7889.0000525

mode (not shown) occurs at the same location and is an elastic-plastic elephant's foot buckling mode (Rotter, 1990). In each case where an analysis under eccentric discharge pressures produced a load factor below unity, the buckling mode was a local, entirely elastic buckle across the channel at approximately midheight (GNA = GMNA). It should be clarified that though the precise location of the buckle depends on the local thickness distribution, the global pattern of membrane stress resultants ( $n$ $=t \sigma$ ) and thus the compressive peak in the axial membrane stress resultant at approximately midheight are insensitive to the local wall thickness.

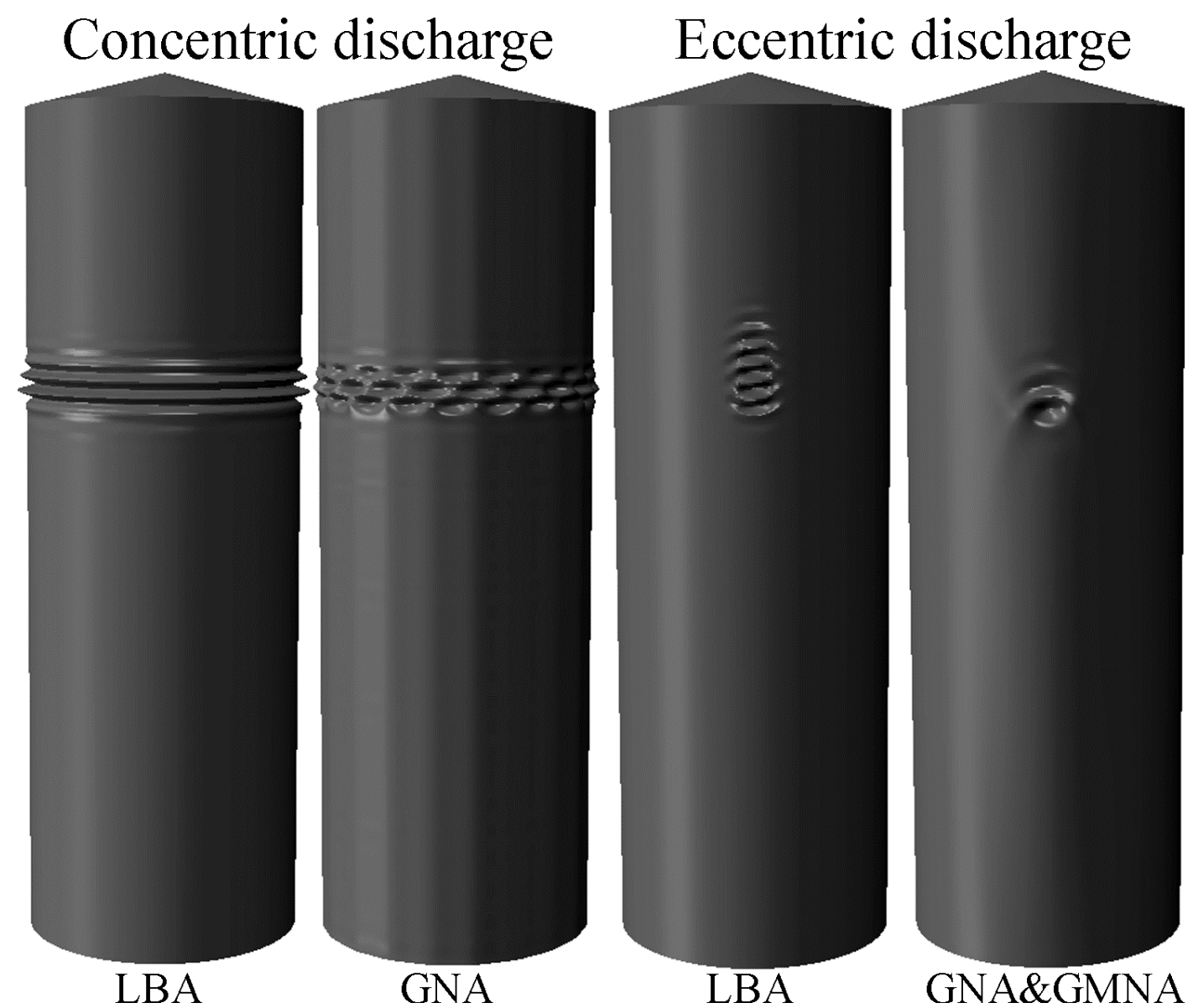

Fig. 8 - Examples of geometrically linear and nonlinear buckling modes

\section{Exploration of the mechanics of geometric nonlinearity}

\subsection{Introduction}

The results presented both here and in previous numerical studies of metal silos under eccentric discharge pressures (Sadowski \& Rotter, 2010; 2011a,b,c,d) consistently show that the predicted nonlinear elastic (GNA) buckling load factors are higher than 
Published in: ASCE Journal of Engineering Mechanics, 139(7), 858-867.

DOI: http://dx.doi.org/10.1061/(ASCE)EM.1943-7889.0000525

the linear bifurcation (LBA) load factors. This effect was also found by Song and Teng (2003), though they used different pressure patterns.

But this finding is rather counter-intuitive. The low pressure zone causes the cylindrical shell to deform inwards, producing a flattening of the wall, which may be interpreted as a higher effective radius to thickness ratio (Rotter, 1985). As a result, it is reasonable to expect that a geometrically nonlinear analysis, which accounts for the changes in shape, will produce lower load factors than a linear analysis which takes no account of changes of shape. Moreover, the extensive literature on shell buckling (e.g. Yamaki, 1984; Rotter, 2004) indicates that geometrically nonlinear analyses will normally produce lower buckling loads, though many of these studies did involve uniform membrane stress states. It is therefore particularly important to establish why a geometrically nonlinear analysis should produce an increase in buckling strength under this loading condition.

The key to the explanation is to separate out two phenomena: the local flattening, which reduces the buckling resistance, and the modified stress distribution caused by geometric nonlinearity which increases it by engaging a larger portion of the shell to resist the local axial compressive force that arises from unsymmetrical pressures. Once these effects have been separated, it is possible to look for situations in which one will dominate over the other, so distinguishing between conditions where geometric nonlinearity will be strengthening and where it will cause a loss of strength.

A clear view of these two effects can be gained if a load case and geometry can be found where the buckling resistance is almost identical in the linear and geometrically nonlinear analyses. Under these conditions, the strengthening and weakening effects are clearly identical in magnitude, so they can be separately evaluated and each explored alone. However, it is not easy to find conditions in which these two effects precisely balance each other, so the description which follows must be seen as an opportunistic exploitation of a fortunate circumstance.

The one special load case in the present study where the linear and geometrically nonlinear (LBA and GNA) buckling load factors were found to be equal was for the eccentric discharge pressure distribution without 'ears' at $k_{\mathrm{c}}=0.25$. The two load 
Published in: ASCE Journal of Engineering Mechanics, 139(7), 858-867.

DOI: http://dx.doi.org/10.1061/(ASCE)EM.1943-7889.0000525

factors were the same to two significant figures (marked in bold, Table 2). This chance occurrence permits a direct comparison to be made between the unsymmetrical membrane stress distributions from the geometrically linear (LA) and nonlinear (GNA) analyses at the same buckling load factor. Such a comparison leads to useful observations about the mechanics involved. Most significantly, it permits the two opposing phenomena described above to be separated because they balance each other for this (and only this) particular case.

\subsection{Stress resultant distributions at buckling from LA and GNA finite element analyses}

The first part of this exploration examines the beneficial effect of a gradually changing global stress resultant distribution which accompanies a geometrically nonlinear analysis. The meridional distributions of axial membrane stress resultants at the centre and at the edge of the flow channel are shown in Fig. 9 at the same load factor in LA and GNA analyses. The two patterns, one with and the other without geometrically nonlinear effects, are both predicted to cause buckling in the same location and at the same load factor. The buckling location is at the base of the thinnest strake and across the centre of the flow channel (Fig. 8). The ratio of the peak compressive membrane stress resultants at this location in the LA and GNA analyses is approximately 2.27 . Thus geometric nonlinearity has reduced the peak membrane compressive stress resultant by $56 \%$, but since buckling occurs in both analyses at the same load factor, the lower stress resultant at buckling in the GNA analysis must be directly attributable to the flattening of the silo wall.

The most naturally expected change in geometry is flattening of the cylindrical wall adjacent to the flow channel. This is best explored by extracting the local radius of curvature of the deformed wall in a GNA analysis. This deformed curvature naturally varies around the circumference, with the highest radius where the wall is flattest and lower radii where the wall must curve sharply to maintain the overall circular form. To illustrate this, the circumferential variation of the local radius of curvature through the critical location at the GNA buckling load factor is shown in Fig. 10. This curvature is easily deduced from the deformed nodal locations by finite difference approximations to the total curvature. The flattening of the wall at the instant of 
Published in: ASCE Journal of Engineering Mechanics, 139(7), 858-867.

DOI: http://dx.doi.org/10.1061/(ASCE)EM.1943-7889.0000525

buckling is considerable. The highest radius of curvature reaches about $7500 \mathrm{~mm}$, which is 2.5 times greater than the undeformed radius of $3000 \mathrm{~mm}$. The classical critical buckling stress resultant (Eq. 1) for this large radius of curvature may be found as $n_{\mathrm{cl}, \text { flat }}=145 \mathrm{~N} / \mathrm{mm}, 60 \%$ lower than the undeformed classical critical value of 363 $\mathrm{N} / \mathrm{mm}$. These values quite closely match, but lie slightly below, the stress resultants calculated in the LBA and GNA analyses at the instant of buckling (Fig. 9). The corresponding values were 166 and 376 N/mm respectively. Flattening of the wall can thus be seen to be the dominant effect in changing the stress resultant that causes buckling. Moreover, wall flattening is clearly very destabilising because buckling now occurs at a much lower critical compressive stress resultant, and remains closely in line with the criterion of buckling at the relevant classical critical value (Eq. 1).

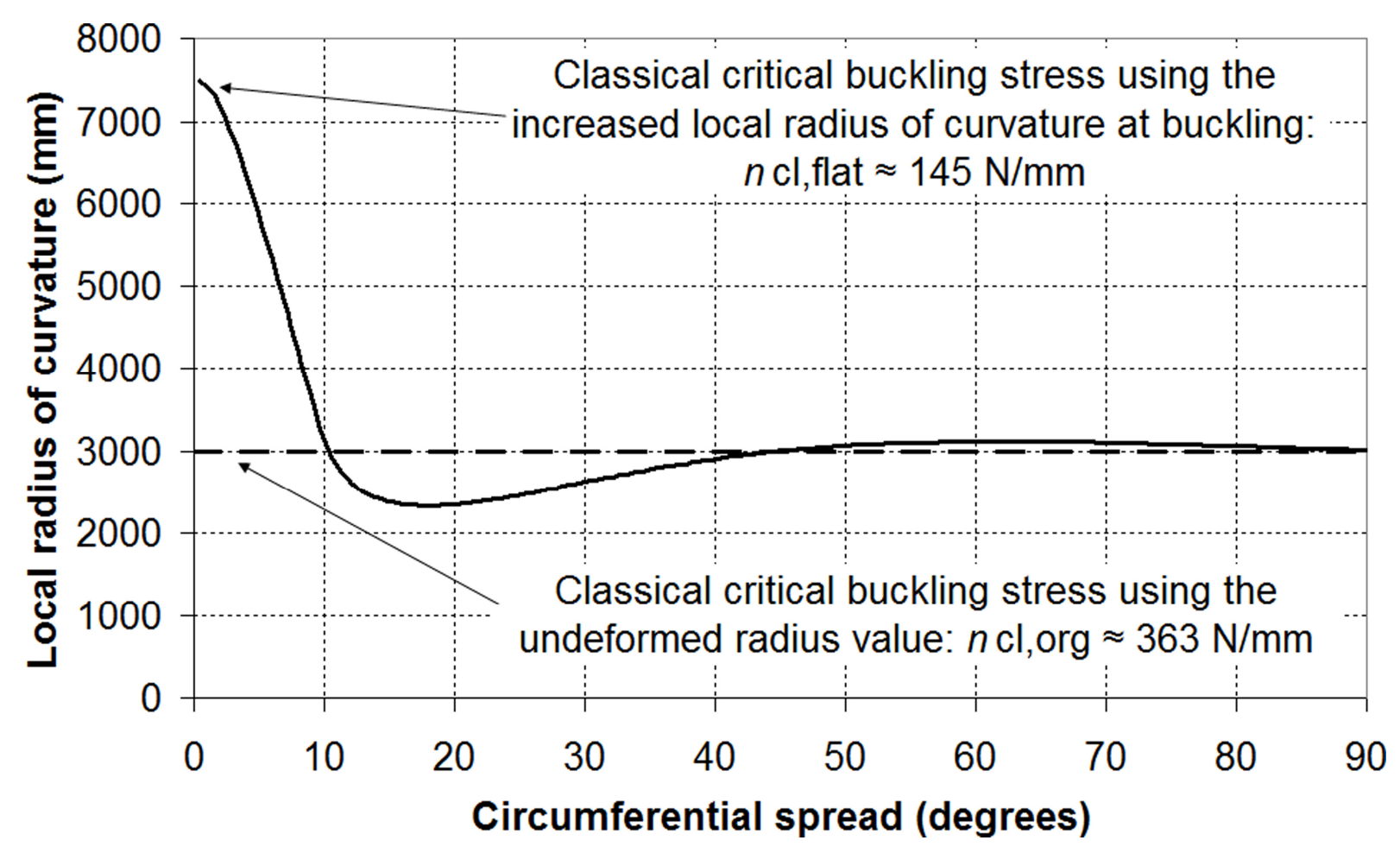

Fig. 9 - Meridional distribution of LA and GNA axial membrane stress resultants at the same buckling load factor at the centre and edge of the flow channel (no 'ears') 
Published in: ASCE Journal of Engineering Mechanics, 139(7), 858-867.

DOI: http://dx.doi.org/10.1061/(ASCE)EM.1943-7889.0000525

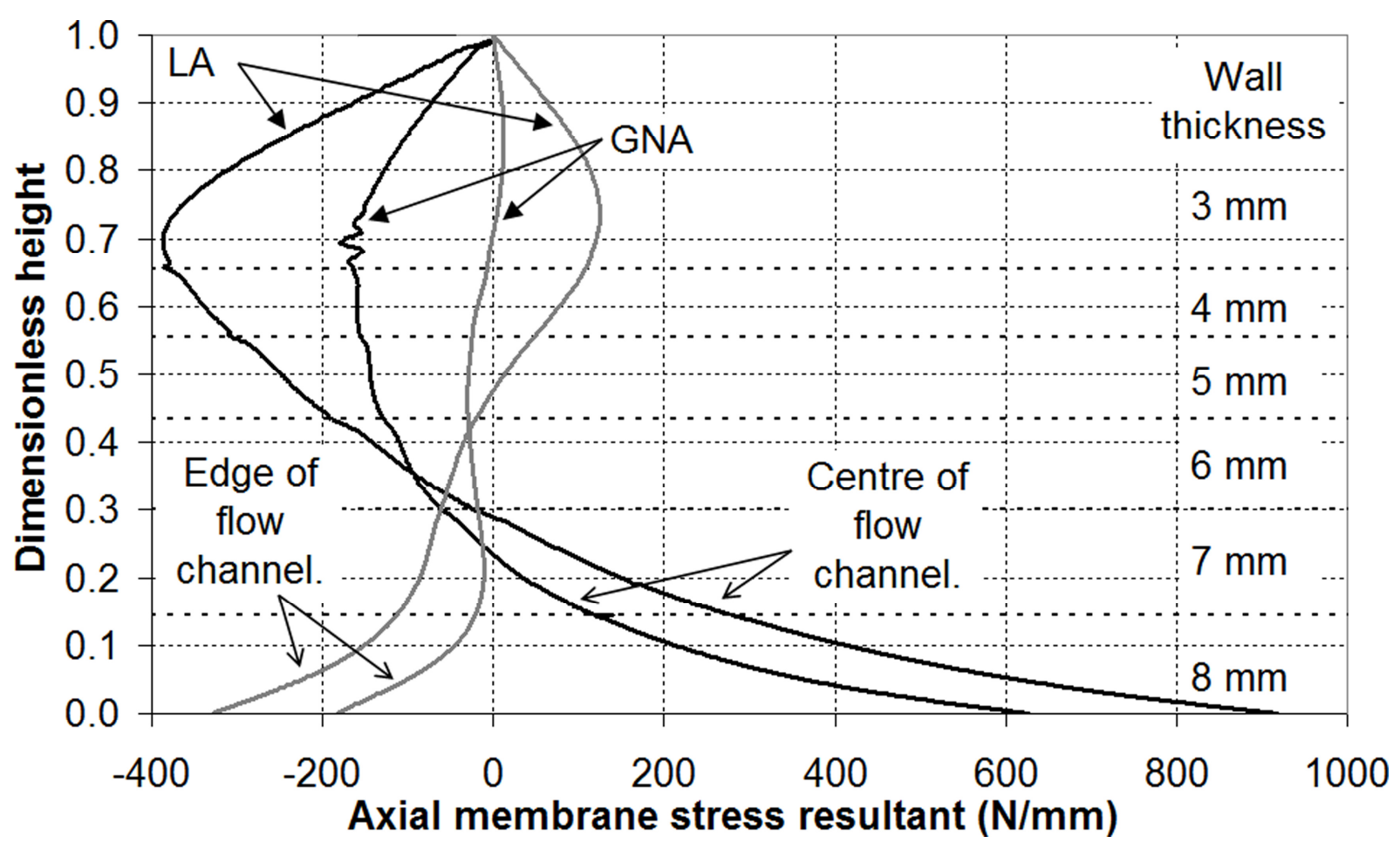

Fig. 10 - Circumferential distribution of the local radius of curvature from a GNA analysis at buckling just above the base of the thinnest wall strake (no 'ears')

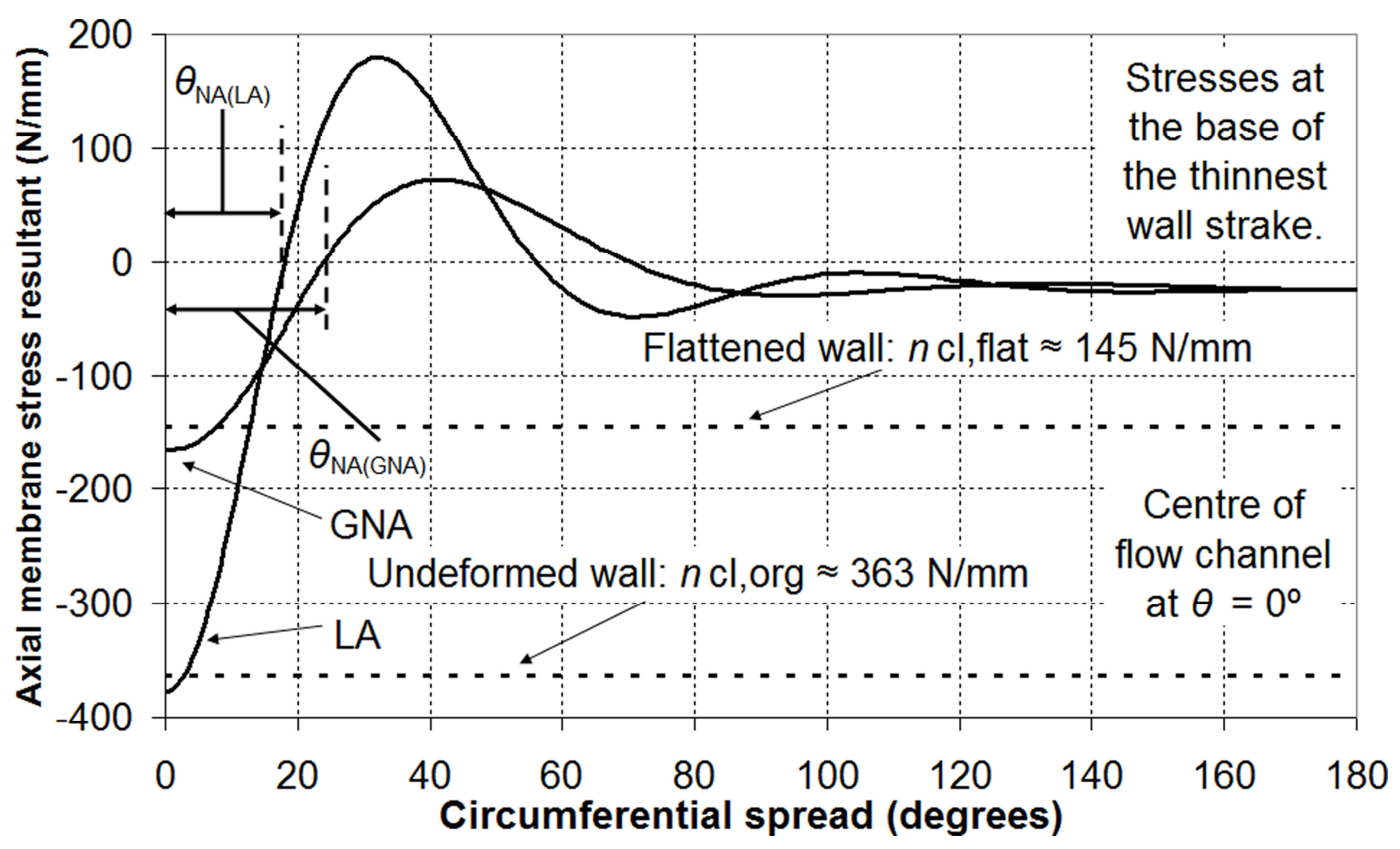

Fig. 11 - Circumferential distribution of LA and GNA axial membrane stress resultants at buckling just above the base of the thinnest wall strake (no 'ears') 
Published in: ASCE Journal of Engineering Mechanics, 139(7), 858-867.

DOI: http://dx.doi.org/10.1061/(ASCE)EM.1943-7889.0000525

The circumferential distributions of LA and GNA axial membrane stress resultants at the location of the buckle and at the point of buckling are shown in Fig. 11. It may be seen that the change of geometry in a GNA analysis causes a greater portion of the shell to be mobilised in carrying the axial membrane stresses, leading to an overall reduction in their magnitudes. The peak compressive values in the LA and GNA analyses clearly correspond very closely to the critical stress resultants $363 \mathrm{~N} / \mathrm{mm}$ and $145 \mathrm{~N} / \mathrm{mm}$ calculated using the original radius and the locally-increased radius of curvature respectively, as discussed previously. The mechanics of this change in geometry are next explored.

\subsection{Propped cantilever analogy}

The vertical distribution of axial membrane stress resultants at the centre of the flow channel (Fig. 9) is similar to the bending moment distribution in a propped cantilever under a distributed transverse load (Fig. 12). The direct stresses in the top fibre of the beam, which are tensile near the built-in support but compressive near the middle of the beam, correspond to the axial membrane stress resultants in the silo at the channel centre. Similarly, the direct stresses in the bottom fibre of the beam correspond approximately to the axial membrane stress resultants at the channel edge. A similar treatment of a cylindrical shell under unsymmetrical loading was described by Briassoulis and Pecknold (1986) and Gould (1988) using the concept of a 'slicebeam'. It should, however, be noted that a beam analysis assumes that plane sections remain plane, which cannot be justified for a shell under unsymmetrical loading. There is thus no reason to suppose a priori that this simple model will be an accurate predictor of the stresses or of the ratios between stresses in the shell.

An example circumferential distribution of axial membrane stress resultants at buckling for the silo under eccentric discharge is shown in the top part of Fig. 13, where the other symmetric half of the distribution has been omitted to give more clarity. The curve oscillates around a reference value, which corresponds to the axisymmetric axial membrane stress resultant in the silo wall due only to friction ( $p_{\text {fse }}$ $=\mu p_{\text {hse }}$, Fig. 3). Removing this axisymmetric component centres the oscillations about zero and divides the distribution into compressive and tensile zones akin to the direct stress distributions in a beam. The extreme fibres of the beam are taken to lie at $\theta=0^{\circ}$ 
Published in: ASCE Journal of Engineering Mechanics, 139(7), 858-867.

DOI: http://dx.doi.org/10.1061/(ASCE)EM.1943-7889.0000525

(bottom fibre) and at some value $\theta=\theta_{\mathrm{C}}$, which must be chosen to make the integral of the compressive stresses equal to the integral of the tensile stresses. The elastic neutral axis of the beam passes through the point of zero stress at some value $\theta=\theta_{\mathrm{NA}}$ which may be determined directly from the circumferential stress distribution.

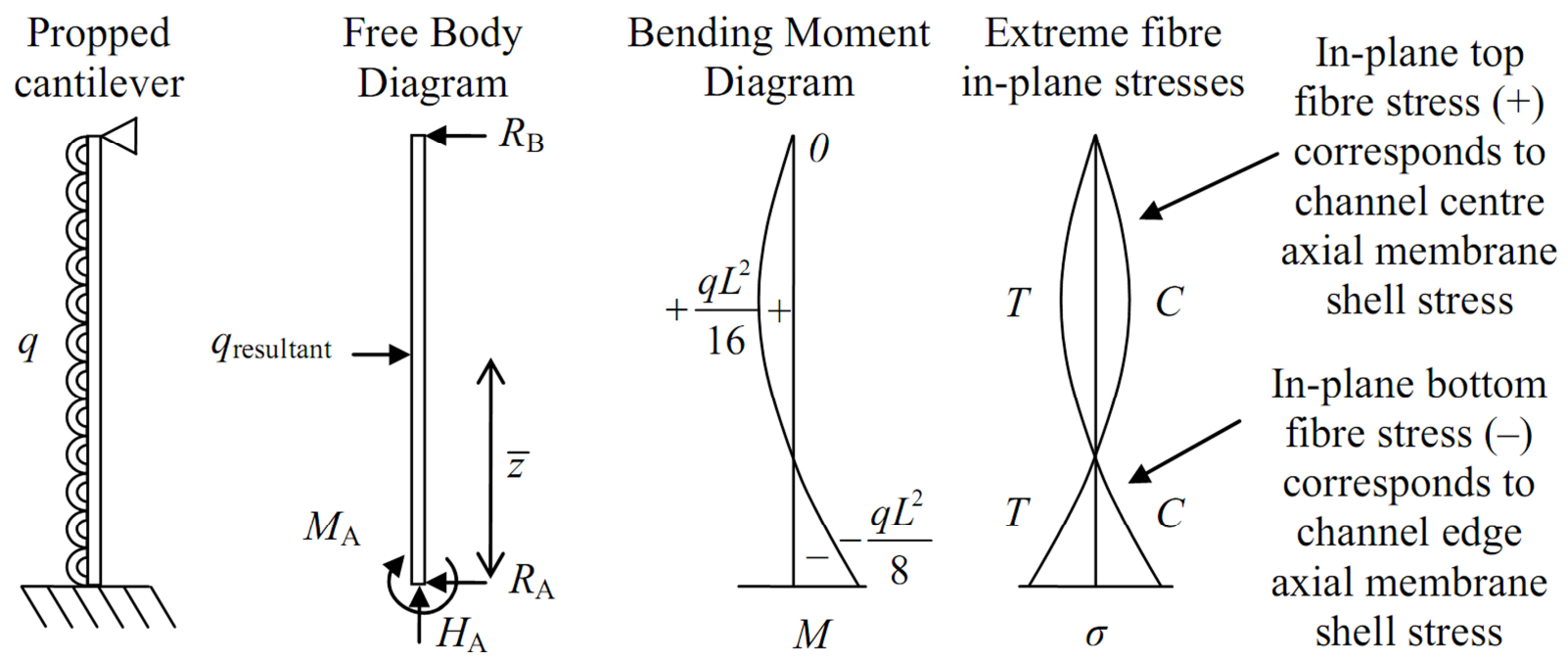

Fig. 12 - Uniform propped cantilever under uniformly distributed transverse load

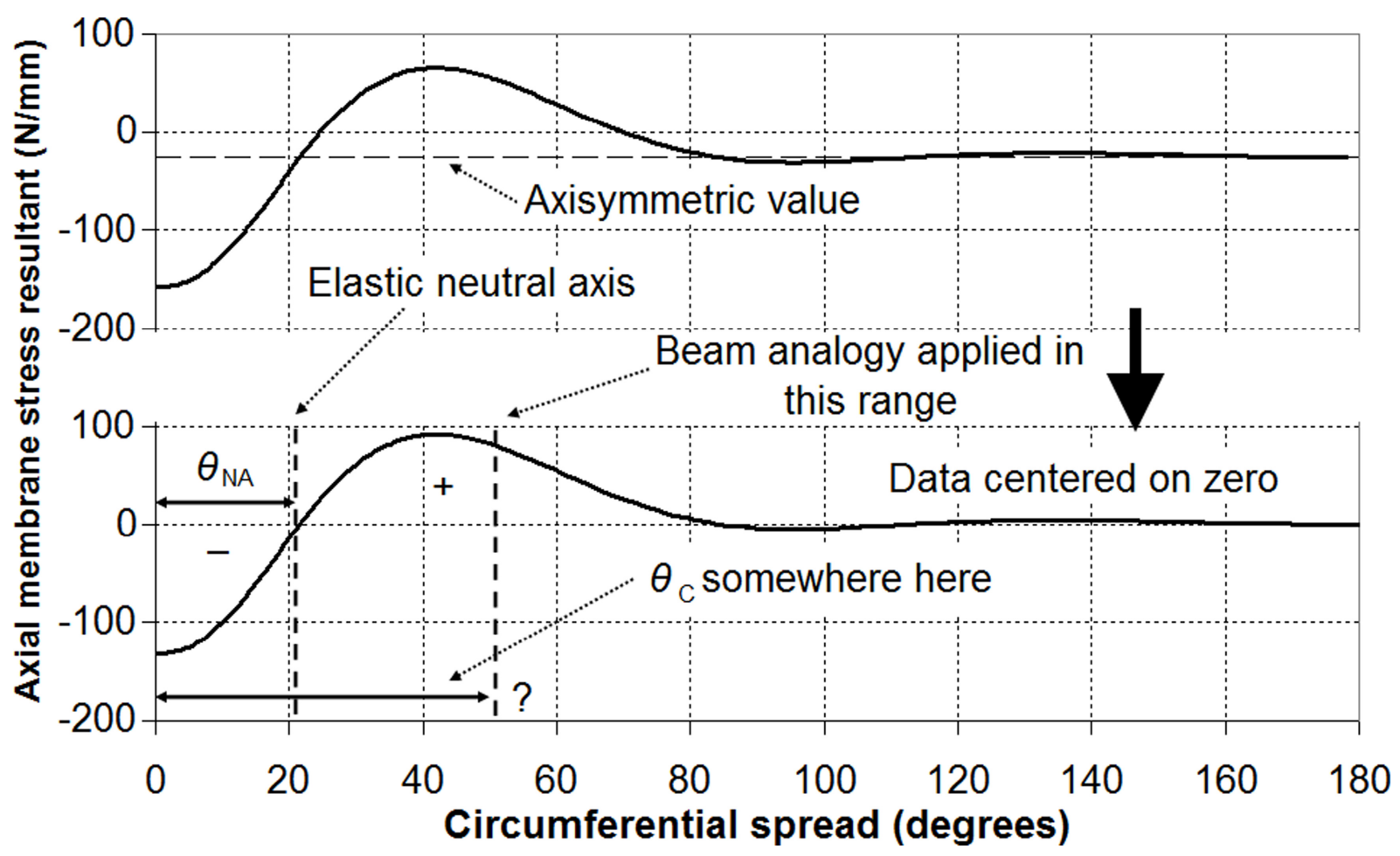

Fig. 13 - Application of a beam analogy to shell behaviour 
Published in: ASCE Journal of Engineering Mechanics, 139(7), 858-867.

DOI: http://dx.doi.org/10.1061/(ASCE)EM.1943-7889.0000525

The beam cross-section is taken here as a thin circular arc $(t<r)$ (Fig. 14). The angle $\theta_{\mathrm{NA}}$ is taken as the point at which the axial membrane stress resultant is zero, but the final coordinate $\theta_{\mathrm{C}}$ must be determined numerically using geometrical relations. The radius and thickness of the circular arc, $r$ and $t$ respectively, are taken as the values in the silo from which the shell stresses were taken. Thus $r=3000 \mathrm{~mm}$ and $t=3 \mathrm{~mm}$.

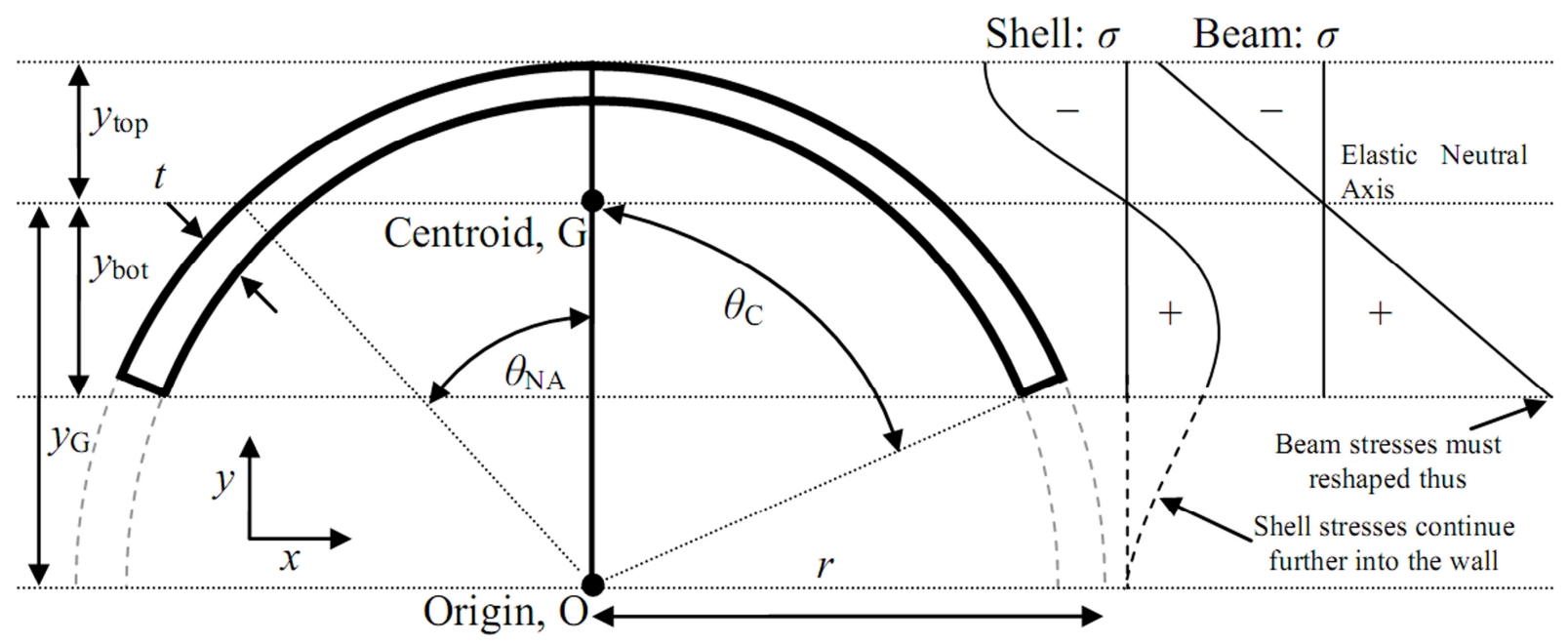

Fig. 14 - Circular arc beam cross-section and in-plane stress distributions

The circular arc (Fig. 14) has the following section properties, assuming $t \ll r$ (Sadowski, 2011):

Area: $A \approx 2 \theta_{C} r t$

Centroid: $y_{G} \approx \frac{2 r(r-t)}{2 r-t} \frac{\sin \theta_{C}}{\theta_{C}}$

Taking $\theta_{\mathrm{NA}}$ as known, the angular extent of the circular arc $\theta_{\mathrm{C}}$ may be obtained as the solution of the transcendental equation:

$y_{G}\left(\theta_{C}\right)=r \cos \theta_{N A}$

The section modulus to the top fibre $Z_{\text {top }}$ is then:

$Z_{\text {top }}=\frac{I_{G}}{r-y_{G}}$

where the second moment of area through the centroidal axis (including the thickwalled $t^{2}$ term for accuracy) is:

$I_{G} \approx \frac{1}{2} r^{2} t(2 r-3 t)\left(\theta_{C}+\sin \theta_{C} \cos \theta_{C}\right)-\frac{4 r^{3} t(r-2 t)}{2 r-t} \frac{\sin ^{2} \theta_{C}}{\theta_{C}}$ 
Published in: ASCE Journal of Engineering Mechanics, 139(7), 858-867.

DOI: http://dx.doi.org/10.1061/(ASCE)EM.1943-7889.0000525

\subsection{Comparison}

The circumferential distributions of LA and GNA axial membrane stress resultants at buckling (Fig. 11) were transformed using this beam analogy to find the corresponding values of $\theta_{\mathrm{NA}}$ and $\theta_{\mathrm{C}}$ as shown in Table 3. The GNA stress pattern produces larger values of both $\theta_{\mathrm{NA}}$ and $\theta_{\mathrm{C}}$, indicating that the section centroid is lower in the GNA stress distribution, and the greater spread of the resulting circular arc produces a much greater second moment of area. The section modulus for the 'GNA beam' is consequently significantly larger than that of the 'LA beam', causing a reduction in the peak direct stresses. This calculation is summarised in Table 3.

Table 3 - Summary of beam analogy calculations and percentage decrease in peak compressive stress due to geometric nonlinearity

\begin{tabular}{|c|c|c|c|c|c|c|}
\hline Analysis & $\theta_{\mathrm{NA}}\left({ }^{\circ}\right)$ & $\theta_{\mathrm{C}}\left({ }^{\circ}\right)$ & $y_{\mathrm{G}}(\mathrm{mm})$ & $Z_{\mathrm{bot}}\left(\mathrm{cm}^{3}\right)$ & $\begin{array}{c}\mathrm{Z}_{\mathrm{bot}(\mathrm{GNA})} \\
\mathrm{Z}_{\mathrm{bot}(\mathrm{LA})}\end{array}$ & $\begin{array}{c}\% \\
\text { decrease }\end{array}$ \\
\hline 'LA beam' & 17.1 & 29.5 & 2868 & 948.2 & & \\
\hline 'GNA beam' & 21.33 & 37.0 & 2795 & 1848.5 & 1.95 & 49 \\
\hline Peak compression in shell & \multicolumn{2}{|c|}{$\sigma_{\max (\mathrm{LA})} / \sigma_{\max (\mathrm{GNA})}\left(\equiv \mathrm{Z}_{\mathrm{bot}(\mathrm{GNA})} / \mathrm{Z}_{\mathrm{bot}(\mathrm{LA})}\right)$} & 2.27 & 56 \\
\hline
\end{tabular}

The previous finding was that the increase in local radius of curvature caused a big reduction in the axial stress at buckling. The test here is to explore whether the increase in the effective section causes a corresponding decrease in the induced axial stress, so that these two effects precisely counteract each other in this special case. This test is only sufficient if the "effective bending moment" in the equivalent beam is unaffected by geometric nonlinearity, or more accurately, if the unsymmetrical axial membrane action in the shell is correspondingly independent.

The test of this hypothesis is made by examining the rise in this effective section modulus and comparing it with the decrease in peak axial stress in the finite element analysis from the linear to nonlinear analyses. The summary in Table 3 shows that the two calculations are in reasonably close agreement: the beam analogy indicates a reduction by a factor of 1.95 , whilst the finite element analysis indicates that this is slightly larger at 2.27. This pair of assessments (one of buckling, the other of induced stresses) indicates that the axial membrane action induced by the non-symmetric loading strip is substantially independent of the linearity or nonlinearity of the 
Published in: ASCE Journal of Engineering Mechanics, 139(7), 858-867.

DOI: http://dx.doi.org/10.1061/(ASCE)EM.1943-7889.0000525

analysis, and that the critical changes due to geometric nonlinearity are dominated by the greater circumferential zone engaged to support it together with the flattening of this zone to reduce the stress required to cause buckling.

This analogy may be generalised to describe the nonlinear behaviour of thin-walled cylindrical shells under a wider range of unsymmetrical strip-like loads acting down a meridian (Sadowski \& Rotter, 2011e, 2012). But some further work is still needed to completely generalise the analogy to produce a reliable semi-empirical approximation to the stress state in silos under eccentric discharge. This is, however, a necessary goal if this disastrous load condition is to be addressed without regular resort to an onerous and complex nonlinear finite element analysis.

\section{Conclusions}

This study has explored both the effect of 'ears' on a pressure distribution that represents eccentric discharge in a thin-walled silo, as well as the mechanics of the changes in buckling resistance from a linear to a geometrically nonlinear analysis.

It may be concluded that:

1) The effect of removing regions of high normal pressure at the edges of an eccentric discharge flow channel (the 'ears') results in a very significant increase in the predicted buckling strength (between approximately 55\% and $115 \%$ ). Nevertheless, it should be noted that both models produce much lower buckling strengths than for concentric discharge. Thus the primary cause of early buckling in slender metal silos under eccentric discharge is a drop in normal pressure in the flowing channel.

2) The mechanics were explored of the two opposing nonlinear effects that occur simultaneously under eccentric discharge: the detrimental effect of local flattening of the silo wall and the beneficial effect of redistribution of stresses around the circumference. For the special case of the smallest flow channel $\left(k_{\mathrm{c}}=r_{\mathrm{c}} / r=0.25\right)$, the LBA and GNA load factors were found to be almost equal, which allowed the separation of the two effects. Two critical findings resulted from this separation.

3) The local stress at the point of buckling under axial compression was shown to be relatively close to the classical axial uniform compression buckling stress 
Published in: ASCE Journal of Engineering Mechanics, 139(7), 858-867.

DOI: http://dx.doi.org/10.1061/(ASCE)EM.1943-7889.0000525

resultant (Eq. 1) when the appropriate local radius of curvature was used in its evaluation (the original radius for LBA or the deformed radius for GNA).

4) The circumferential patterns of the axial membrane stress resultant under linear and nonlinear analyses were explored. It was found that geometric nonlinearity causes the axial stress resultant from locally reduced normal pressures to be distributed over a greater circumferential portion of the shell wall. Using the analogy of a propped cantilever beam, the GN beam crosssection was found to have a much higher section modulus, producing a reduction in the direct stress at the extreme fibre by a factor of approximately 2 for the same bending moment. This reduction corresponded very closely to the reduction seen from linear to geometrically nonlinear in the finite element calculations.

5) The combined effects of geometric nonlinearity in reducing the stresses that cause buckling whilst simultaneously increasing the susceptibility to buckling can thus be seen as the cause of either rises or falls from the linear bifurcation to the geometrically nonlinear buckling strength in unsymmetrically loaded cylindrical shells. This explanation should be of value in further studies of unsymmetrically loaded thin cylinders.

\section{References}

ABAQUS (2009). “ABAQUS Version 6.9” Dassault Systèmes Simulia Corp., Providence, RI, USA. www.simulia.com

AS 3774 (1996). "Loads on bulk solids containers" Standards Australia, Sydney.

Briassoulis D. \& Pecknold D.A. (1986). "Behaviour of empty steel grain silo under wind loading: Part 1: the stiffened cylindrical shells" Engineering Structures, 8(4), 260-274.

Bucklin R.A., Thompson S.A. \& Ross I.J. (1990). "Bin-Wall Failure Caused by Eccentric Discharge of Free-Flowing Grain” Jrnl. of Struct. Eng., ASCE, 116(11), 3175-3189. 
Published in: ASCE Journal of Engineering Mechanics, 139(7), 858-867.

DOI: http://dx.doi.org/10.1061/(ASCE)EM.1943-7889.0000525

Chen J.F. (1996). "Granular Solid - Structure Interaction in Silos" PhD Thesis, The University of Edinburgh, UK.

Chen J.F., Rotter J.M. \& Ooi J.Y. (1998). "Statistical inference of unsymmetrical silo pressures from comprehensive wall strain measurements" Thin-Walled Structures, 31, 117-136.

Chen J.F., Rotter J.M., Ooi J.Y. \& Zhong Z. (2007). "Correlation between the flow pattern and wall pressures in a full scale silo" Engineering Structures, 29, 2308-2320.

DIN 1055-6 (1987). "Design loads for buildings: loads in silo bins" Deutsches Institut für Normung, Berlin, Germany.

EN 1991-4 (2006). "Eurocode 1: Actions on Structures, Part 4: Silos and Tanks" Comité Européen de Normalisation, Brussels.

EN 1993-1-6 (2007). "Eurocode 3: Design of Steel Structures, Part 1-6: Strength and Stability of Shell Structures" Comité Européen de Normalisation, Brussels.

EN 1993-4-1 (2007). "Eurocode 3: Design of Steel Structures, Part 4.1: Silos" Comité Européen de Normalisation, Brussels.

Gale B.R., Hoadley P.J. \& Schmidt L.C. (1986). “Aspects of Eccentric Discharge of Granular Material from a Circular Silo" Proc. of the 2nd Int. Conf. on Bulk Materials Storage, Handling and Transportation, IEAustralia, Wollongong, 258-263.

Gould P.L. (1988). "Cylindrical Shell Slice-Beam" Jrnl. of Eng. Mech., ASCE, 114(5), 905-911.

ISO 11697 (1995). "Basis for design of structures - loads due to bulk materials" International Standards Organisation.

Jenike A.W. (1967). "Denting of Circular Bins with Eccentric Drawpoints" J. of the Sruct. Div., ASCE, 93 (ST1) 27-35. 
Published in: ASCE Journal of Engineering Mechanics, 139(7), 858-867.

DOI: http://dx.doi.org/10.1061/(ASCE)EM.1943-7889.0000525

Nielsen J. \& Kristiansen N.O. (1980). "Related measurements of pressure conditions in full-scale barley silo and in model silo" Proc. Int. Conf. on Design of Silos for Strength and Flow, Lancaster, UK, 1-23.

Ooi J.Y., Pham L. \& Rotter J.M. (1990). "Systematic and random features of measured pressures on full-scale silos" Engineering Structures, 12(2), 74-87.

Pieper K. \& Wenzel F. (1964). "Druckverhältnisse in Silozellen” Wilhelm Ernst und Sohn, Berlin.

Riks E. (1979). “An incremental approach to the solution of snapping and buckling problems" Int. J. Solids Struct, 15, 529-551.

Roberts A.W. \& Ooms M. (1983). "Wall loads in large metal and concrete silos and silos due to eccentric draw-down and other factors" Prof. 2nd Int. Conf. on Design of Silos for Strength and Flow, Stratford-upon-Avon, UK, 151-170.

Rotter J.M. (1985). "Design under axial compression” Design of Steel Bins for the Storage of Bulk Solids, ed. J.M. Rotter, The University of Sydney, Australia, 122-137.

Rotter J.M. (1986). "The analysis of steel bins subject to eccentric discharge" Proc. of the 2nd Int. Conf. on Bulk Materials Storage, Handling and Transportation, IEAustralia, Wollongong, 264-271.

Rotter, J.M. (1990) "Local Inelastic Collapse of Pressurised Thin Cylindrical Steel Shells under Axial Compression”, Journal of Structural Engineering, ASCE, Vol. 116, No. 7, July 1990, pp 1955-1970.

Rotter J.M., Jumikis P.T., Fleming S.P. \& Porter S.J. (1989). "Experiments on the buckling of thin-walled model silo structures" Journal of Constructional Steel Research, 13(4), 271-299. 
Published in: ASCE Journal of Engineering Mechanics, 139(7), 858-867.

DOI: http://dx.doi.org/10.1061/(ASCE)EM.1943-7889.0000525

Rotter J.M. (2001a). "Guide for the Economic Design of Circular Metal Silos" Spon Press, London \& New York.

Rotter J.M. (2001b). "Pressures, Stresses and Buckling in Metal Silos containing Eccentrically Discharging Solids" Festschrift Richard Greiner, Celebration volume for the $60^{\text {th }}$ birthday of Prof. Richard Greiner, TU Graz, Austria, October, 85-104.

Rotter J.M. (2004). "Buckling of cylindrical shells under axial compression" Chapter 2 in Buckling of Thin Metal Shells, eds J.G. Teng \& J.M. Rotter, Spon, London, 4287.

Sadowski A.J. \& Rotter J.M. (2010). “A Study of Buckling in Steel Silos under Eccentric Discharge Flows of Stored Solids" Jrnl. of Eng. Mech., ASCE, 136(6), 769776.

Sadowski A.J. \& Rotter J.M. (2010). "Study of buckling in steel silos under eccentric discharge flows of stored solids" ASCE Journal of Engineering Mechanics, 136(6), $769-776$.

Sadowski A.J. (2011). "Geometric properties for the design of unusual member crosssections in bending" Engineering Structures, 33(5), 1850-1854.

Sadowski A.J. \& Rotter J.M. (2011a). "Buckling of very slender metal silos under eccentric discharge" Engineering Structures, 33(4), 1187-1994.

Sadowski A.J. \& Rotter J.M. (2011b). "Steel silos with different aspect ratios: I behaviour under concentric discharge" Journal of Constructional Steel Research, 67(10), 1537-1544.

Sadowski A.J. \& Rotter J.M. (2011c). "Steel silos with different aspect ratios: II behaviour under eccentric discharge" Journal of Constructional Steel Research, 67(10), 1545-1553. 
Published in: ASCE Journal of Engineering Mechanics, 139(7), 858-867.

DOI: http://dx.doi.org/10.1061/(ASCE)EM.1943-7889.0000525

Sadowski A.J. \& Rotter J.M. (2011d). "The structural behaviour of thin-walled metal silos subject to different flow channel sizes under eccentric discharge pressures" ASCE Journal of Structural Engineering, 138(7), 922-931.

Sadowski A.J. \& Rotter J.M. (2011e). "Different computational analyses and the behaviour of thin-walled cylindrical shells under unsymmetrical strip loads" Proc. 6th Int. Conf. on Thin-Walled Structures, 5-7 September, Timisoara, Romania, 969-976.

Sadowski A.J. \& Rotter J.M. (2012). "Slender thin cylindrical shells under unsymmetrical loads" Accepted for publication in Thin-Walled Structures. DOI: http://dx.doi.org/10.1016/j.tws.2012.03.021.

Song, C.Y. and Teng, J.G. (2003) "Buckling of circular steel silos subject to codespecified eccentric discharge pressures", Engineering Structures, Vol. 25, No. 11, Sept 2003, pp. 1397-1417.

Watson D. \& Niland D. (2009). "Bucking Experiments on Silos under Eccentric Discharge" BEng theses, The University of Edinburgh, UK.

Wood J.G.M. (1983). "The Analysis of Silo Structures Subject to Eccentric Discharge" Proc. of the $2^{\text {nd }}$ Int. Conf. on Design of Silos for Strength and Flow, Stratford-upon-Avon, 132-144.

Yamaki N. (1984). "Elastic Stability of Circular Cylindrical Shells" North-Holland, Amsterdam. 